\title{
Perfiles generales de la COSa juzgada en el Derecho Procesal Civil brasilero $^{(* *)\left({ }^{(* *}\right)}$
}

\section{Overall profiles of the res judicata in the Brazilian Civil Procedual Law}

Resumen: El objetivo de este escrito es ofrecer al lector, especialmente al extranjero, un panorama general de la cosa juzgada en derecho procesal civil brasilero, con un enfoque especial (no el único) en el tratamiento dado al tema por el Código del Proceso Civil de 2015. La primera parte del texto analiza un conjunto de situaciones, bastante peculiares en realidad, de la propia autoridad de la cosa juzgada y sus matices; para luego en un segundo momento tratar temas clásicos de los límites objetivos y subjetivos, y el régimen peculiar de cosa juzgada de las acciones colectivas. Finalmente, el objetivo es analizar los perfiles generales del instituto, sin detenerse en polémicas o especificaciones propias de una perspectiva de derecho interno.

Palabras Clave: Cosa Juzgada - Derecho Procesal Brasilero - Límites Objetivos y Subjetivos - Acciones Colectivas - Seguridad Jurídica

\begin{abstract}
The purpose of this paper is offer to the reader, especially to the foreign reader, an overall picture of the res judicata en the Brazilian civil procedural law, with a special approach (not the only one) in the treatment to this topic by the Procedual Civil Code of 2015. The first part analyses a set of situaciones, quite peculiar actually, of the own authority of the res judicata along its shades; then, secondly, treats classical themes of the objective and subjective limits, and the peculiar regimen of the collective actions of the res judicata. Finally, the main is to analyze the overall profiles of the institute, without stopping in controversies or specifications regarding the perspective of the domestic law.
\end{abstract}

Keywords: Res Judicata - Brazilian Procedual Law - Objective and Subjective Limits - Collective Actions - Legal Certainty

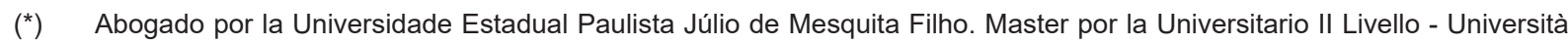
degli Studi di Roma "Tor Vergata". Doctor en Derecho Procesal de la Facultad de Derecho de la Universidad de Sao Paulo, Profesor de Derecho Procesal Civil de la Escuela de Ribeirão Preto de Derecho de la Universidad de Sao Paulo. Correo electrónico: camilo@usp.br.

${ }^{(* *}$ La traducción estuvo a cargo del Magíster Gilberto Mendoza del Maestro. Profesor de Derecho Civil de la Pontificia Universidad Católica del Perú. Correo electrónico: gmendoza@pucp.pe.

${ }^{* * *}$ Nota del editor: Este artículo fue recibido el 05 de noviembre de 2016 y su publicación fue aprobada el 15 de noviembre del mismo año. 


\section{Perfiles generales de la cosa juzgada en el Derecho Procesal Civil brasilero Overall profiles of the res judicata in the Brazilian Civil Procedual Law}

\section{Previsión de la cosa juzgada en el derecho positivo brasilero}

El derecho brasilero le reconoce a la cosa juzgada status de norma constitucional, en función a la mención expresa en el artículo 5, que trata de los derechos y garantías de los ciudadanos, en su inciso XXXV|(1), al mencionar que la ley no perjudica el derecho adquirido, el acto jurídico perfeccionado y la cosa juzgada.

Evidentemente que la terminología constitucional dice menos de lo deseable, ya que la cosa juzgada no sólo puede ser violada por la ley, sino por cualquier otra conducta, pública o privada, que retire su fuerza legal. Esta naturaleza constitucional del instituto es muy importante porque además de dimensionar la importancia socio-jurídica del instituto, en la medida en que representa lo indispensable de la seguridad jurídica en un Estado Democrático de Derecho, brinda fundamentos para tener acceso al Supremo Tribunal Federal (en adelante, "STF"), Corte de Justicia brasilera responsable del análisis y control de cuestiones constitucionales, como inclusive ha ocurrido recientemente.

En el campo infraconstitucional, la Ley de Introducción a las Normas de Derecho Brasilero, todavía de forma general e imprecisa, por lo menos desde el punto de vista procesal, estipula que la ley en vigor tendrá efecto inmediato y general, respetando el acto jurídico perfeccionado, el derecho adquirido y la cosa juzgada, concibiendo esta última como la decisión judicial sobre la que no cabe recurso, claramente confundiendo la decisión judicial en sí con la autoridad que recubre el mandato de la decisión judicial capaz de otorgar la calidad de cosa juzgada. De todos modos, se trata de una norma de naturaleza general y la mención al instituto debe ser visto como una referencia al principio de seguridad jurídica y no con relación a los precisos elementos técnicos del proceso.

En el campo estrictamente procesal, el régimen jurídico de la cosa juzgada se divide en dos grandes núcleos fundamentales: el Código del Proceso Civil de 2015, que establece el sistema de la cosa juzgada para los conflictos de natulaeza individual; y el código de defensa del consumidor de 1990, que en su parte procesal, establece el sistema de cosa juzgada, para los conflictos de naturaleza colectiva.

Además de estas dos leyes importantes, existen normas especiales que se ocupan de aspectos específicos, tales como la ley de alimentos, de aplicación a los conflictos individuales, y el mandato de seguridad colectiva, para conflictos colectivos, ${ }^{(2)}$ entre otros.

Pero sin duda, el tratamiento más amplio y estructural de la cosa juzgada, se encuentra en el mismo Código del Proceso Civil, pues ahí se establece el concepto, las premisas fundamentale del tema, los límites objetivos y otras reglas generales del tema, tales como la eficacia de lo deduzido e do dedutível.

(1) Artículo 5. Todos são iguais perante a lei, sem distinção de qualquer natureza, garantindo-se aos brasileiros e aos estrangeiros residentes no País a inviolabilidade do direito à vida, à liberdade, à igualdade, à segurança e à propriedade, nos termos seguintes: (...).

XXXVI - a lei não prejudicará o direito adquirido, o ato jurídico perfeito e a coisa julgada (...).

(2) Ley 5478/68: Artículo 15. La decisión judicial sobre la comida no se convierte en definitiva y podrá, en cualquier el tiempo se revisará teniendo en cuenta el cambio en la situación financiera de las personas afectadas; Ley 12.016 / 2009: Artículo 22. En el mandamiento de seguridad colectivo, la sentencia será cosa juzgada de forma limitada a los miembros de grupo o categoría reemplazados por el peticionario. Curiosamente, grabo que estos dos dispositivos sufren serias críticas de la doctrina brasileña. El primero porque dice que no hay formación de cosa juzgada en la acción de la comida cuando en realidad no, pero inmutabilidad es condicional no cambia los hechos que marcan la comida; si el cambio de éstos es revisional acción adecuada de los alimentos. La segunda porque adopta una postura restrictiva de beneficiarios de cosa juzgada forman en la demanda colectiva, lo que limita sus efectos a los sujetos vinculados al autor sustituto procesal de la demanda. 
Camilo Zufelato

Existe en lo que respecta a los límites subjetivos de cosa juzgada el punto divergente entre el sistema individual y el sistema colectivo, dado que en el primero la regla es la restricción inter partes, y en el segundo es la extensión erga omnes o ultra partes, con sus características, como se verá a continuación.

\section{Concepto de cosa juzgada en el derecho brasilero, repercusiones y aspectos críticos}

De acuerdo con el artículo 502 del CPC (en adelante, "CPC") brasilero, se denomina cosa juzgada material la autoridad que torna inmutable e indiscutible la decisión de fondo ya no sujeta a recurso, revelando prima facie la influencia de las enseñanzas de Liebman no sólo en la doctrina, como siempre ha sido reconocida, sino también en la legislación.

Esto es debido a que el CPC derogado, aunque la intención era también para rendir homenaje al procesalista italiano que tanta acogida tuvo en la doctrina brasileña, fue aprobado llamando cosa juzgada a la eficacia de la sentencia ${ }^{(3)}$, lo que revela la confusión derivada de los cambios en el proceso legislativo y no del proyecto Buzaid, autor del código, sobre la distinción clásica entre la eficacia y la autoridad de cosa juzgada en la obra de Liebman ${ }^{(4)}$. El hecho es que la cosa juzgada, como no podría dejar de ser, es un instituto de gran relevancia en el derecho brasilero y siempre ha sido objeto de atención por parte de la doctrina. ${ }^{(5)}$

Es bien conocida la doctrina del procesalista brasilero Barbosa Moreira al precisar que la inmutabilidad de la cosa juzgada hace inmutable, en la realidad, no la decisión en sí misma, o sus efectos, toda vez que estos pueden ser alterados inclusive por la voluntad de las partes, pero sí el contenido de la decisión
(1971) complementando de manera crítica el trabajo de Liebman.

Otro cambio significativo a tomar en cuenta sobre el concepto de cosa juzgada adoptada por el CPC de 2015 es que la inmutabilidad recaerá sobre la decisión de fondo, y no sobre la sentencia sobre el fondo, tal como señalaba el código antiguo.

La razón que justifica este cambio es el hecho de que el código dota a ciertas resoluciones interlocutorias, que juzgan el fondo, de aptitud para formar la cosa juzgada tal como si fuese una sentencia. De hecho, lo importante para reconocer la aptitud de una decisión para formar cosa juzgada no es su naturaleza, sino su contenido: debe ser decisión de fondo.

Además, como resultado, este cambio afecta a la idoneidad de la acción rescisoria, porque esta no será más la acción que rescinde sólo la sentencia (o la resolución que volvió a examinar la materia juzgada por sentencia), sino también este tipo de decisiones interlocutorias de fondo. En resumen, tanto la formación de la cosa juzgada material como su rescisión, ocurre cuando la decisión, sea cual fuere aprecia el fondo. ${ }^{(6)}$

Un ejemplo de tal decisión de fondo apta a formar cosa juzgada material es el denominado juzgamiento anticipado parcial sobre el fondo previsto en el artículo 356 ${ }^{(7)}$ del CPC 2015 que autoriza al juez para dividir el fondo de una

(3) Artículo 467 de la cosa 1973 CPC se denomina eficiencia de los materiales juzgados, lo que hace que no cambia y frase indiscutible, ya no susceptibles de recurso ordinario o extraordinario.

(4) En la traducción brasileña: Liebman, Enrico Tullio. La eficacia y la autoridad de la sentencia y otros escritos de cosa juzgada (con las modificaciones relativas a la ley brasileña), $3^{a}$ ed. Río de Janeiro: Forense.

(5) Cónfer algunos clásicos monográfico escrito sobre el tema en la ley procesal civil brasileña: Celso Neves, Contribución al estudio de cosa juzgada civiles (Sao Paulo: Revista de los Tribunales, 1970); Sergio Gilberto Porto, Res civiles juzgada, $3^{a}$ ed. (Río de Janeiro: Aide, 2006); José María Tesheiner, Juicio de las juzgada eficacia y resolución en un procedimiento civil (Sao Paulo: Revista de las Cortes de 2002), además, por supuesto, los numerosos y excelentes escritos de José Carlos Barbosa Moreira.

(6) Artículo 966: La decisión sobre el fondo, cosa juzgada, se puede terminar cuando: [...]

(7) Do Julgamento Antecipado Parcial do Mérito 


\section{Perfiles generales de la cosa juzgada en el Derecho Procesal Civil brasilero Overall profiles of the res judicata in the Brazilian Civil Procedual Law}

demanda y juzgar anticipadamente uno de los pedidos o parte de ellos cuando ese se muestra incontrovertido o estuviera en condiciones de juzgamiento anticipado por dispensa de otras pruebas.

En verdad el legislador no ha expresado la naturaleza de esa decisión que juzga anticipadamente el fondo, pero determina que esta será impugnable por medio del recurso de agravio de instrumento que procede contra las decisiones interlocutorias, de manera que la doctrina nacional ha afirmado que ese acto es una decisión interlocutoria (por tanto no una sentencia) pasible de formar cosa juzgada material.

En verdad y a pesar del derecho positivo vigente, prefiero considerar que desde el punto de vista sustancial la decisión que juzga parcial y anticipadamente el fondo continúa siendo sentencia, pues en nada se distingue, desde el punto de vista de su contenido y de la cognición judicial emprendida, de la decisión final del fondo que pone fin la fase cognitiva del procedimiento común (Artículo $203 \S 1)^{(8)}$.

Además, inclusive pone fin la faz cognitiva relativa a la cuestión de fondo juzgada anticipadamente. Es claro que reconocer que tal decisión es sentencia (como además la doctrina anterior a la vigencia del CPC del 2015 denominaba sentencia parcial sobre el fondo, en comentarios a los artículos 273 § 6 del CPC de $1973^{(9)}$ ) genera un problema de naturaleza recursiva, pues afectaría la apelación (que también fue llamada apelación por instrumento), y en consecuencia el tradicional envío integral de los autos al Tribunal.

Ahora bien, esta cuestión de orden practico sería fácilmente superable, admitiéndose la cabida, por ejemplo del recurso de agravio de instrumento contra esta, sólo esta, sentencia, resolviendo asi el impase de orden practico, sin tener que alterar el tradicional pensamiento de que la cosa juzgada se forma de las sentencias que resuelven el fondo.

El artículo en cuestión también confirma la notoria distinción entre cosa juzgada formal y material. La primera, considerada una etapa de toda y cualquier sentencia, puesto que se forma a partir de la imposibilidad de impugnarla, es la única que se constituye cuando se emita sentencia sin resolución de fondo. Por eso la cosa juzgada formal sólo se forma en el propio proceso en la cual fue declarada, sin vincular, como presupuesto

Artículo 356. O juiz decidirá parcialmente o mérito quando um ou mais dos pedidos formulados ou parcela deles:

I - mostrar-se incontroverso;

II - estiver em condições de imediato julgamento, nos termos do art. 355.

$\S 1^{\circ} \mathrm{A}$ decisão que julgar parcialmente o mérito poderá reconhecer a existência de obrigação líquida ou ilíquida.

§ 20 A parte poderá liquidar ou executar, desde logo, a obrigação reconhecida na decisão que julgar parcialmente o mérito, independentemente de caução, ainda que haja recurso contra essa interposto.

§ $30 \mathrm{Na}$ hipótese do § 20, se houver trânsito em julgado da decisão, a execução será definitiva.

§ 40 A liquidação e o cumprimento da decisão que julgar parcialmente o mérito poderão ser processados em autos suplementares, a requerimento da parte ou a critério do juiz.

$\S 50$ A decisão proferida com base neste artigo é impugnável por agravo de instrumento.

(8) Artículo 203. Os pronunciamentos do juiz consistirão em sentenças, decisões interlocutórias e despachos. $\S 1^{\circ}$ Ressalvadas as disposições expressas dos procedimentos especiais, sentença é o pronunciamento por meio do qual o juiz, com fundamento nos arts. 485 e 487, põe fim à fase cognitiva do procedimento comum, bem como extingue a execução.

(9) Artículo 273. O juiz poderá, a requerimento da parte, antecipar, total ou parcialmente, os efeitos da tutela pretendida no pedido inicial, desde que, existindo prova inequívoca, se convença da verossimilhança da alegação e: (Redação dada pela Lei 8.952, de 1994) I - haja fundado receio de dano irreparável ou de difícil reparação; ou (Incluído pela Lei 8.952, de 1994) II - fique caracterizado o abuso de direito de defesa ou o manifesto propósito protelatório do réu. (Incluído pela Lei 8.952, de 1994) (...)

$\S 60$ A tutela antecipada também poderá ser concedida quando um ou mais dos pedidos cumulados, ou parcela deles, mostrar-se incontroverso. (Incluído pela Lei 10.444, de 2002) 
Camilo Zufelato

procesal negativo, que es propio del instituto en comentario, a otros jueces en procesos futuros, al final, el fondo todavía no fue apreciado, por tanto, se admite interposición de la acción fundada en la misma lid.

En cambio, la cosa juzgada material no, toda vez que se forma sobre la decisión que resolvió el fondo, y por esa razón adquiere autoridad de inmutabilidad para todo y cualquier proceso futuro.

Sin embargo pese a la tradicionalísima construcción doctrinaria distinguiendo las dos modalidades, es cada vez mayor el numero de doctrinarios brasileros que afirman que solamente la ultima podría ser llamada cosa juzgada; la primera, exactamente por no tener el mismo grado de inmutabilidad, no sería mas que una preclusión máxima.

Noto también que para la renovación de la acción sobre la cual hubo formación de cosa juzgada formal, la doctrina señalaba la necesidad de corrección de los vicios de naturaleza procesal que habían generado la extinción del hecho sin juzgamiento sobre el fondo. Sin tal adecuación, no habría interés procesal en la nueva interposición de la demanda ya extinta sin restitución de fondo.

En ese mismo sentido el artículo 486 del CPC de 2015 dice que "el pronunciamiento judicial que no resuelve el fondo no obsta a que la parte proponga de nuevo la demanda. En caso de extinción en razón de litispendencia y los casos de los incisos I, IV, VI Y VII del articulo 585 [denegar la petición inicial; verificar la ausencia de presupuestos de constitución y de desenvolvimiento valido y regular del proceso; verificar ausencia de legitimidad o de interés procesal; acoger la alegación de existencia de la convención de arbitraje o cuando el juicio arbitral reconoce su competencia], la interposición de la nueva demanda depende de la corrección del vicio que llevó la sentencia sin resolución de fondo" (resaltado del autor), dejando claro lo que parte de la doctrina ya señalaba.

Esa autoridad, que es connatural y propia del instituto de cosa juzgada material, recientemente pasó por un processo de cierta inestabilidad en Brasil, como si fuese condicionada la justicia o la constitucionalidad de la decisión. En otras palabras, se pasó a admitir la relativilizacion de la cosa juzgada material, incluso después del plazo de dos años de la acción rescisoria (que es la accion típica para rescindir la cosa juzgada cuando existan vícios graves, el rol taxativo previsto en el artículo 966 del CPC del $2015^{(10)}$ ) en ciertas hipotesis consideradas excepcionales, con base en dos posibilidades fundamentalmente: i) por expresa previsión legal cuando la ley o acto normativo en el cual se basó la sentencia firme viene a ser declarada inconstitucional por el Supremo Tribunal Federal; y ii) por

(10) Artículo 966. A decisão de mérito, transitada em julgado, pode ser rescindida quando: I - se verificar que foi proferida por força de prevaricação, concussão ou corrupção do juiz; II - for proferida por juiz impedido ou por juízo absolutamente incompetente; III - resultar de dolo ou coação da parte vencedora em detrimento da parte vencida ou, ainda, de simulação ou colusão entre as partes, a fim de fraudar a lei; IV - ofender a coisa julgada; 226 código de processo civil V - violar manifestamente norma jurídica; $\mathrm{VI}$ - for fundada em prova cuja falsidade tenha sido apurada em processo criminal ou venha a ser demonstrada na própria ação rescisória; VII - obtiver o autor, posteriormente ao trânsito em julgado, prova nova cuja existência ignorava ou de que não pôde fazer uso, capaz, por si só, de lhe assegurar pronunciamento favorável; VIII - for fundada em erro de fato verificável do exame dos autos. $\S 1^{\circ}$ Há erro de fato quando a decisão rescindenda admitir fato inexistente ou quando considerar inexistente fato efetivamente ocorrido, sendo indispensável, em ambos os casos, que o fato não represente ponto controvertido sobre o qual o juiz deveria ter se pronunciado. $\S 2^{\circ}$ Nas hipóteses previstas nos incisos do caput, será rescindível a decisão transitada em julgado que, embora não seja de mérito, impeça: I - nova propositura da demanda; ou II - admissibilidade do recurso correspondente. § $3^{\circ} \mathrm{A}$ ação rescisória pode ter por objeto apenas 1 (um) capítulo da decisão. $\S 4^{\circ}$ Os atos de disposição de direitos, praticados pelas partes ou por outros participantes do processo e homologados pelo juízo, bem como os atos homologatórios praticados no curso da execução, estão sujeitos à anulação, nos termos da lei. 


\section{Perfiles generales de la cosa juzgada en el Derecho Procesal Civil brasilero Overall profiles of the res judicata in the Brazilian Civil Procedual Law}

construccion pretoriana, aliada a la posicion doctrinaria, relacionada básicamente con la injusticia de la sentencia firme.

Em cuanto a la primera posibilidad, actualmente prevista em el artículo 525, parágrafos 12 al 15 del CPC del 2015(11), y también en el artículo 535 , parágrafos 5 al $8^{(12)}$, que se refieren a la impugnación en las ejecuciones contra la Hacienda Pública - lo que se tiene es una hipótesis de inexigibilidad del título ejecutivo judicial en función de la decisión del STF que declara inconstitucional la ley o acto normativo sobre el cual se funda la decisión condenatoria.

Los referidos dispositivos legales regulan la impugnación al cumplimiento de la sentencia, de manera que la relación con la autoridad de la cosa juzgada es esta: aunque halla formación de cosa juzgada sobre la sentencia de fondo que está en fase de cumplimiento forzado, todavía sería posible, tornar inexigible el título, retirar el efecto positivo de la autoridad de cosa juzgada aunque sin dejar sin efecto la decisión. En otros términos, la peculiaridad de esta figura consiste en hacer retroceder una decisión del STF que declara inconstitucional una norma que fundamenta un proceso, tornando el título ejecutivo judicial en inexigible, por tanto alterando la autoridad de la cosa juzgada.

La solución del legislador causa asombro y perplejidad, pues a primera vista se nota un claro debilitamiento de la seguridad jurídica y de la estabilidad de las relaciones que parece vulnerar totalmente la autoridad de cosa juzgada. Esa es la posición de la amplísima mayoría de la doctrina brasilera.
En verdad la redacción de los nuevos dispositivos tienta a mitigar los excesos que el artículo 475-L del CPC de 1973 contenía, pues prácticamente no había límites para que la declaración de inconstitucionalidad retrocediese para violar la cosa juzgada, y los actuales parágrafos de los artículos 525 y 535 imponen ciertos límites a esa retroactividad de la decisión del STF, especialmente los 13, 14 y 15.

Ahora bien, incluso así me parece que son claramente inconstitucionales, pues continuan violando la seguridad jurídica y la estabilidad en el Estado Democrático de Derecho, sobretodo el parágrafo 15 que, absurdamente, crea hipótesis de acción rescisória con base en la posterior declaración de inconstitucionalidad.

Ad argumentandum, sólo recuerdo que el origen de estos dispositivos en la ley brasileña se deriva de la medida provisoria $2.180-35$ de 2001, posteriormente convertida en Ley, que introdujo el párrafo único en el artículo 741 del CPC 1973, permitiendo que la Hacienda Pública se valiese de tal expediente para impedir la ejecución en su contra en casos, por ejemplo, declaración de inconstitucionalidad de cierto tributo, dejando evidente el motivo que inspiro al legislador a violar el principio de seguridad jurídica propio de la cosa juzgada.

(11) “§ 12. A los efectos de la fracción III del § 1 de este artículo, también se considera inaplicable la la responsabilidad de la ejecución judicial basada en la ley o normativa acto considerado inconstitucional por el Tribunal Supremo, o en base a la aplicación o interpretación de la ley o acto normativo adoptado por el Tribunal Supremo Federal por ser incompatible con la Constitución, en control de constitucionalidad concentrado o difuso. § 13. En el caso del § 12, los efectos de la decisión Tribunal Supremo puede ser modulada en el tiempo, de acuerdo con la seguridad jurídica. § 14. la decisión del Tribunal Supremo se refiere el $\S 12$ debe ser anterior a la decisión final e inapelable exigible. $§ 15$. Si la decisión mencionada en el $\S 12$ se emite después de la decisión final e inapelable exigible, será la acción de rescisión, que este período se contará a partir de la sentencia definitiva contra la decisión por el Tribunal Supremo".

(12) Artículo 535. A Fazenda Pública será intimada na pessoa de seu representante judicial, por carga, remessa ou meio eletrônico, para, querendo, no prazo de 30 (trinta) dias e nos próprios autos, impugnar a execução, podendo arguir: I - falta ou nulidade da citação se, na fase de conhecimento, o processo correu à revelia; II - ilegitimidade de parte; III - inexequibilidade do título ou inexigibilidade da obrigação; IV - excesso de execução ou cumulação indevida de execuções; V - incompetência absoluta ou relativa do juízo da execução; VI - qualquer causa modificativa ou extintiva da obrigação, como pagamento, nova- ção, compensação, transação ou prescrição, desde que supervenientes ao trânsito em julgado da sentença. 


\section{Camilo Zufelato}

La segunda posibilidad se refiere a la llamada teoría de la relativización de la cosa juzgada, que se originó en los inicios de los años 2000 a partir de algunos procesos y de respetables posiciones doctrinarias, según las cuales la autoridad de la cosa juzgada no es un valor en sí mismo y por eso tiene que compatibilizarse con otros valores de naturaleza constitucional. Luego, según esta teoría, cuando se verifique la violación de ciertos principios constitucionales de elevado estatus, aunque la decisión fuese sometida a la firmesa de la autoritas rei iudicati, la injusticia sería tan evidente que justificaría una relativización de la cosa juzgada formada, incluso se encuentre fuera de plazo y de las hipótesis exhaustivas de la acción rescisoria ${ }^{(13)}$. Esa teoría tuvo como situaciones concretas, por ejemplo, indemnizaciones pagadas indebidamente por el Estado, o incluso las acciones de paternidad cuando no hubiese habido pruebas de ADN.

El hecho es que inmediatamente al surgimento y defensa de la teoría de relativizacion de la cosa juzgada, se hizo sentir con vigor la posición contraria de la doctrina procesal que criticó ferozmente los riesgos a la seguridad jurídica y a la estabilidad de las relaciones que tal postura generaba, pues vulneraría de forma casi absoluta los principios democráticos que están representados en el instituto de la cosa juzgada, en la medida en que mal utilizada, la teoría de la relativización podría permitir infinitas rediscuciones bajo el pretexto de buscar corregir una injusticia/inconstitucionalidad. Felizmente, en nuestro sentir, perdió fuerza la defensa de tal teoria, lo que se dio a partir de duras criticas de respetable doctrina nacional, pues en efecto, violaba las funciones de estabilidad y autoridad de cosa juzgada.

Una hipótesis que fue considerada como ejemplo de relativización de la cosa juzgada, que continúa siendo admitida en las demandas de investigación de paternidad cuando hubiera cosa juzgada formada sobre la demanda en la cual no se realizó el examen de ADN como prueba de paternidad.

Más que eso: la construcción jurisprudencial se actualizó, en el ámbito del STJ, así como fue reconocida su constitucionalidad por el STF. Sin embargo, esa hipótesis no es en realidad una sumisión de inmutabilidad del proceso a la justicia de la decisión, en el sentido de autorizarse la reapertura de la instrucción simplemente para coger otras pruebas que permitan una decisión más cerca a la realidad, pero sin permitir la realización de un medio de prueba cuya tecnología era inexistente en el momento de la tramitación de la acción, siendo por tanto una prueba técnica, que en este caso bordea el cien por ciento de certeza, el criterio objetivo y seguro de injusticia de la primera decision.

Considerando que la prueba de ADN es inexistente al momento de la tramitación de la demanda con formación de cosa juzgada, esa prueba es considerada superveniente, o sea que sale a la luz solamente después que la autoridad haya juzgado, lo que constituía un tipo de cosa juzgada denominada secundum eventum probationis, vale decir condicionada al tipo de tecnología en que se fundaba la prueba sobre la paternidad.

Otro aspecto reciente y que tiene bastante interés se vincula con una modalidad creada por el CPC de 2015 la cual, aunque mucho se asemeje, en el fondo sería distinta de la

$\S 5^{\circ}$ Para efeito do disposto no inciso III do caput deste artigo, considera-se também inexigível a obrigação reconhecida em título executivo judicial fundado em lei ou ato normativo considerado inconstitucional pelo Supremo Tribunal Federal, ou fundado em aplicação ou interpretação da lei ou do ato normativo tido pelo Supremo Tribunal Federal como incompatível com a Constituição Federal, em controle de constitucionalidade concentrado ou difuso. $\S 6^{\circ}$ No caso do $\S 5^{\circ}$, os efeitos da decisão do Supremo Tribunal Federal poderão ser modulados no tempo, de modo a favorecer a segurança jurídica. $\S 7^{\circ}$ A decisão do Supremo Tribunal Federal referida no $\S 5^{\circ}$ deve ter sido proferida antes do trânsito em julgado da decisão exequenda. $\S 8^{\circ} \mathrm{Se}$ a decisão referida no $\S 5^{\circ}$ for proferida após o trânsito em julgado da decisão exequenda, caberá ação rescisória, cujo prazo será contado do trânsito em julgado da decisão proferida pelo Supremo Tribunal Federal.

(13) Candido Rangel Dinamarco, "Relativizar a coisa julgada material, " Revista Forense, v. 358, 11-32; José Miguel Garcia Medina; Teresa Arruda Alvim Wambier, O dogma da coisa julgada - hipóteses de relativização (São Paulo: Revista dos Tribunais, 2003); Eduardo Talamini, Coisa julgada e sua revisão (São Paulo: Saraiva, 2005). 


\section{Perfiles generales de la cosa juzgada en el Derecho Procesal Civil brasilero Overall profiles of the res judicata in the Brazilian Civil Procedual Law}

verdadera y propia cosa juzgada. Se trata de la estabilidad de la tutela anticipada, que en líneas generales se constituye de la siguiente manera (Artículo 304): una vez concedida la tutela anticipada, si no es impugnada por el demandado, adquiere estabilidad con la consecuente extinción del proceso, pero los efectos de la tutela concedida continuará produciendo efectos desde que el demandado no proponga, en el plazo de dos años, accion propia para reformar, anular o invalidar la tutela.

Tal estabilidad se da, por tanto en situaciones de tutela satisfactiva de condición sumaria, en las cuales tiene conocimiento el demandado con la anticipación provisional basada en la urgencia (sea por la no contestación, sea por la no impugnación recursiva) más queda abierta la posibilidad de atacar tal estabilidad, puesto no se trata de cosa juzgada material, una vez que el propio legislador se encargó de despejar cualquier duda a ese respecto: la decisión que concede la tutela no hará cosa juzgada, más la estabilidad de los respectivos efectos sólo será alejada por decisión que la revive, reforma o invalida, dictada en la demanda interpuesta por una de las partes, en los términos del $\S 2$ de este artículo (§ 6 del articulo 304). Pensando en dilaciones temporales, estabilizada la tutela anticipada, la parte tendrá dos años para revivir, reformar o revalidar tal decisión, al fin de los cuales se inicia el plazo, también de dos años para tener al final, ahí si, la formación de la cosa juzgada material.

El instituto es innovador, desde el punto de vista del derecho positivo anterior y pretende claramente traer una situación de ventaja a la parte que obtiene una anticipación de tutela con conocimiento del demandado. Sin embargo, considero que hubo un tratamiento equicovado de la figura. Esa solución de establecer una estabilidad anterior a la autoridad de cosa juzgada es rastro de una visión tradicional que merecería ser dejada atrás, que la cognición es un atributo indispensable para la formación de la cosa juzgada. En la gran mayoría de los procedimentos lo es. Más es posible tambien pensar en situaciones (la tutela satisfactiva sumaria de urgencia sería una de essas) en la que el conocimiento del demandado es el elemento más que justificador de modo que, a pesar de la cognición judicial no ha sido exhaustiva, es suficiente para la concesión de la medida que no recibió impugnación por la contraparte.

En este sentido, considero que el legislador se perdió la oportunidad de innovar más y dar un paso adelante rumbo a autorizar la formación de la cosa juzgada material a partir de la cognición sumaria con conocimiento del demandado.

Por último, hay un aspecto muy controvertido en que se refiere a la autoridad de la cosa juzgada en el desarrollo reciente de la jurisprudencia brasileña, que no es precisamente del ámbito civil, sino penal, aunque en última instancia, podría incluso suscitar reflexiones importantes en la jurisdicción civil. Se trata de la sentencia del Supremo Tribunal Federal que afirmó la posibilidad de tenerse por iniciado el cumplimiento de la pena, en consecuencia de la condena penal antes de la decisión final; o dicho en otro término, la presunción de inocencia, garantizada constitucionalmente en Brasil ya no estará sujeta a la formación de cosa juzgada para comenzar a cumplir su condena.

De acuerdo con esta línea, significa que al decir, en el artículo 5, párrafo LVII, que se ocupa de los derechos y garantías fundamentales, "que nadie puede ser considerado culpable hasta que se emita una sentencia penal condenatoria" la Constitución Federal brasileña no condicionaría el inicio de pena de prisión a que exista resolución con calidad de cosa juzgada, sin que esso afectase al principio de presunción de inocencia.

Preliminarmente hay que aclarar que el doble grado de jurisdicción en el país se compone de una amplia revisión de la resolución impugnada en el ámbito del tribunal local a través de los recursos ordinarios, y luego todavía habría recursos, extraordinarios, ya que existe limitación de materias, a los tribunales superiores. En el caso concreto la resolución fue dictada en sede de habeas corpus al STF.

En el proceso de este caso, en el que el demandado había sido condenado en el Tribunal de Justicia de São Paulo, el STF entendió que las condenaciones del segundo 
Camilo Zufelato

grado que confirman las condenas pueden ser ejecutadas inmediatamente, incluso que estén pendientes medidas junto a los Tribunales Superiores con el objetivo de revertir la condena, pues el análisis probatorio y de materialidad estaría agotado en las instancias inferiores. Existió el mismo argumento en el sentido de que cuando existe la confirmación de condena en segundo grado, no habría más presunción de inocencia del acusado, de manera que no sería absolutamente necesario que la condena tenga la calidad de cosa juzgada para que se diese inicio a la ejecución de la pena.

La decisión no fue tomada en sede de expediente con fuerza vinculante, al igual que con otras decisiones emitidas por el STF, pero sin duda es un caso que abre una discrepancia jurisprudencial significativa, pues va en contra de como el propio Tribunal venía resolviendo. Esta reciente posición marcada por fuertes discrepancias entre los propios jueces, tomada en febrero de 2016, no está inmune a críticas severas. A pesar de que un país tenga muy altos niveles de criminalidad y corrupción, la ejecución anticipada de la pena atrae y parece ir en sentido de combatir tales males; de mi parte, considero que la dimensión garantista del debido proceso legal consagrado por el Estado Democrático de Derecho es absolutamente contrario a las interpretaciones judiciales que promueven el retroceso en la protección de los derechos fundamentales. Admitir la ejecución de la pena cuando todavía siga siendo posible la anulación de la condena por los tribunales superiores, de modo que quede claro que hubo privación injusta de libertad del imputado antes de la formación de cosa juzgada, es admitir la violación de la presunción de inocencia.

En este sentido, basado en el valor en cuestión en caso del proceso penal, es decir, el derecho a la libertad del acusado, la cosa juzgada es el límite necesario e indispensable para autorizar el inicio del cumplimiento de la pena. La questión de fondo de este tema en cierta medida tiene fuerte relación con la justicia civil y el acondicionamiento de la formación de la cosa juzgada para la producción de efectos de una decisión judicial. El dogma de que sólo hay ejecución cuando hay inmutabilidad de la cosa juzgada es todavía fuertemente adoptada en el derecho procesal brasileño, que sigue manteniendo la ejecución provisional como situación excepcional, aunque la naturaleza de los derechos en juego es muy diferente del penal y que merecería una amplia revisión legislativa.

\section{Límites objetivos da la cosa juzgada}

El tema de los límites objetivos de la cosa juzgada se trató en el CPC de 1973 de la forma más restrictiva posible: la inmutabilidad de la decisión recaía exclusivamente en la parte dispositiva de la decisión en la medida en que esa es la respuesta a la petición de tutela jurisdiccional establecida por las partes. Eso significa que las cuestiones prejudiciales nunca, aunque fuesen juzgadas em el curso del proceso, quedarían inmunes a la cosa juzgada, pudiendo ser siempre nuevamente discutidas en demandas futuras ${ }^{(14)}$.

El Código también establecía en su artículo 4, una posibilidad extremadamente formal para promover una extensión de los límites

(14) Doctrina más tradicional, bajo los auspicios de la CPC 1973: Thereza Arruda Alvim, Preguntas preliminares y límites objetivos de la cosa juzgada (Sao Paulo: Revista de los Tribunales, 1977); Ovidio Baptista de Silva, Límites objetivos de la cosa juzgada en la ley brasileña actual. En: Sentencia y cosa juzgada - ensayos y $4^{a}$ ed. Opiniones, (Río de Janeiro: Forense, 2013): 103-137; José Carlos Barbosa Moreira, Preguntas y cosa juzgada (Río de Janeiro: Borsoi, 1967); José Carlos Barbosa Moreira, "Límites objetivos de la cosa juzgada en el nuevo sistema de Código de Procedimiento Civil," Temas de Derecho el procedimiento civil (1977): 90-96; José Carlos Barbosa Moreira, "Cosa juzgada - límites objetivos," Derecho aplicado, vol. II.: 439-461; José Carlos Barbosa Moreira, "Preclusiva eficacia de la cosa juzgada en el sistema procesal civil Brasileño," Cuestiones de derecho procesal (1977): 97-109; Ronaldo Cunha Campos, Límites objetivos de la cosa juzgada (Río de Janeiro: Aide, 1988); Ada Pellegrini Grinover, "Consideraciones sobre la eficacia objetivos y límites preclusiva de cosa juzgada," Revista de Síntesis derecho civil y procesal civil 16: 22-29; MEZQUITA, José Ignacio Botelho Mezquita, "La autoridad cosa juzgada y la inmutabilidad de la sentencia de la motivación," Tesis, estudios y evaluaciones del proceso civiles, vol. 2, (2005): 97-154. 


\section{Perfiles generales de la cosa juzgada en el Derecho Procesal Civil brasilero Overall profiles of the res judicata in the Brazilian Civil Procedual Law}

objetivos de la cosa juzgada a las cuestiones prejudiciales, la llamada acción de declaratoria incidental, por medio de la cual las partes podrían proponer una verdadera acción, incidenter tantum, con el fin de promover una ampliación en el objeto del processo, de manera que la cuestión prejudicial se transformaría en cuestión principal, y en consecuencia de esto estaría cubierta por la autoridad de cosa juzgada. Más el procedimento era extremadamente formalista, y en la realidad bien poco utilizado en la práctica.

El CPC de 2015, inclusive a partir de las reflexiones doctrinarias ${ }^{(15)}$, en un movimiento que expande los límites objetivos de la cosa juzgada, mantiene la regla general de limitación de la cosa juzgada a la cuestión principal (artículo 503). La decisión que juzga total o parcialmente el fondo, tiene fuerza de ley en los límites de la cuestión principal expresamente decidida- pero al mismo tiempo, promueve la extensión de las cuestiones prejudiciales, debiendo cumplir algunos requisitos: § 1. Lo dispuesto en el caput se aplica a las resoluciones de cuestión prejudicial, decidida expresa y eventualmente en el proceso, si: I - De esta resolución depende el juzgamiento del fondo; II - Entorno a él han existido contradictorios previos y efectivos, no aplicándose en caso de ausencia; III-El juicio tiene competencia en razón de la materia y de la persona para resorverla como cuestión principal.

En este sentido, se observa que el nuevo código permite la expansión de la autoridad de cosa juzgada a la cuestión prejudicial pero se requiere que tal decisión haya sido expresa, es decir, el juez haya resuelto de manera clara e inequívoca tal cuestión, no estando autorizado a contemplar tal extensión cuando la resolución de una cuestión prejudicial fuere implícita.

Los demás requisitos están relacionados con la propia noción técnica de que una cuestión prejudicial, es decir, cuestión de fondo que necesariamente debe ser apreciada antes de la cuestión principal, de la cual esa tiene dependencia jurídica; la decisión emitida por el juez competente para el juzgamiento de la cuestión prejudicial (exigencia obvia del principio del juez natural) así como la cuestión haya sido sometida al amplio, efectivo y previo contradictorio, alejándose la extensión en caso de ausencia, exactamente porque el imputado revela no tener si quiera conocimiento de que la cuestión prejudicial podría ser extendida a la cosa juzgada, y sobretodo porque, como revela que el és, no puede participar del contradictorio en lo que se refiere al análisis de la cuestión prejudicial para que esa también tuviese fuerza de cosa juzgada.

En el $\S 2$ del mismo artículo se nota una especie de presupuesto negativo para que haya la extención a la cuestión prejudicial, vale decir, no puede haber cualquier tipo de restricciones probatorias o limitaciones a la cognición judicial que impidan al juez apreciar la cuestión prejudicial. Este requisito, en nuestro concepto, es inherente a la propia situación de análisis de una cuestión prejudicial en todo y cualquier proceso, y por tal razón no necesitaría estar expresamente previsto en la ley, pues en caso haya, en función de las limitaciones probatorias o cognitivas, imposibilidad de análisis adecuado de la cuestión prejudicial (y tales limitaciones pueden ocurrir, por ejemplo, en ciertos procedimientos especiales) en realidad lo que habrá será una imposibilidad de análisis de la propia cuestión principal, puesto que independientemente del aspecto de la extensión o no de la cosa juzgada a la cuestión prejudicial, el hecho es que esa siempre inexorablemente deberá ser resuelta por el juzgador en la medida en que la condición para el análisis de la cuestión principal.

En el límite, si no hay adecuación procedimental en relación al aspecto probatorio o cognitivo en lo correspondiente a la cuestión prejudicial, el juez deberá convertir el rito de todo el proceso a fin de que, después de resolver la cuestión prejudicial, ahí se aprecie la cuestión principal.

Finalmente, considero que las novedades relativas a los límites objetivos de la cosa juzgada no reside propiamente en la posibilidad (sólo la posibilidad, una vez que se mantiene la regla general de restricción al pedido principal) de extensión de la inmutabilidad a las cuestiones prejudiciales, puesto que esto era posible, por iniciativa de las partes, incluso en el código del 73, y que de alguna manera aún 


\section{Camilo Zufelato}

no es automática, aunque facilitado por la falta de necesidad de interposición de una demanda, pues como hemos visto está sometida a una serie de requisitos para que abarque la cuestión prejudicial, pero sí en la posibilidad de que el propio juez, incluso sin la iniciativa de las partes, al darse cuenta que deberá enfrentar una cuestión prejudicial (y por tanto observar los requisitos expuesto arriba, haciendo que la inmutabilidad a ella se extienda). Esa novedad, por tanto, no depende tanto de la iniciativa de las partes, pues esa ya existía, pero sí de tratamiento, ex officio, de una cuestión prejudicial apta para ser resuelta.

El punto es que el derecho positivo brasilero, en lo relativo a los límites objetivos de la cosa juzgada, se mantiene fiel a la idea de que son las partes, en el momento de la presentación de la demanda y la contestación, que definen cuales son las cuestiones principales y las cuestiones prejudiciales, de forma que todo el pedido que no fuera expresamente traído por el demandante y el demandado no quedará inmune por la fuerza de la cosa juzgada, pudiendo em cualquier momento, ser deducido en otra demanda, puesto que no existe resolución firme.

La lógica brasilera es bastante formalista y pro partes, en el sentido que queda siempre abierta la vía de apreciación de hechos derivados de uma misma causa petendi si ese pedido no fue invocado por las partes en el curso de la primera demanda.

La cuestión en este punto está estrechamente relacionada con la eficacia preclusiva de cosa juzgada, también llamada de eficacia do deduzido e do dedutíble, que según el código vigente, íntegramente fiel al código derogado, una vez formada la cosa juzgada, se considerarán deducidas y repelidas todas las alegaciones y las defensas que la parte podría oponerse tanto al acogimiento como al rechazo del pedido (Artículo 508).
Queda claro que la cosa juzgada recubrirá sólo las alegaciones y defensas no deducidas expressamente en los limites del pedido, quedando fuera de tal exhautividad otros pedidos que no fueran deducidos voluntariamente por las partes.

De hecho, la cosa juzgada en el derecho positivo brasilero no recubre las situaciones jurídicas no pedidas, ni siquiera em las hipótesis en que existe un fraccionamiento de un derecho en proceso, como ocurre en Italia por ejemplo(16).

Esa opción brasilera, extremadamente restrictiva y en contraposición de otras experiencias extranjeras, como es el caso de Francia, refleja la cultura procesal nacional en este punto especificamente, la cual está muy centrada en principio de la demanda, para lo cual las partes, especialmente la demandante, es la que define el objeto de la prestación jurisdicional y por consecuencia los límites de la inmutabilidad de la cosa juzgada de la que deriva.

Todavía respecto a los límites objetivos a la cosa juzgada, el código se mantiene fiel a la tradición del derecho procesal civil brasileño que no hace cosa juzgada los motivos, si bien es importante para determinar el alcance de la parte dispositiva de la sentencia y la verdad de los hechos, establecidos como fundamento de la sentencia, en los términos del artículo 504. Realmente, el motivo o la verdad de los hechos no están aptos, por sí solos, a someterse a la

(15) Antonio Paso Cabral, Cosa juzgada y preclusões dinâmicas 2a ed. (Salvador: Juspodivm, 2014); Luiz Dellore, "La expansión de los límites objetivos de la cosa juzgada en el nuevo Código de Procedimiento Civil," Revista de Información Legislativa 190 (2011): 35-43; Antonio Aiepi; José Maria Tesheiner; Marilia Zanella Prates, "Límites objetivos de la cosa juzgada en el proyecto de Código de Procedimiento Civiles: reflexiones inspiradas en la experiencia americana," Revista Proceso 194 (abril 2011): 99 y siguientes; Bruno Vasconcelos Carrilho Lopes, Límites objetivos y preclusiva eficacia de cosa juzgada (Sao Paulo: Saraiva, 2012); Teresa Arruda Alvim Wambier, "¿Qué está cubierto por cosa juzgada derecho procesal civil brasileña: la normativa vigente y las perspectivas de cambio," Revista de Proceso 230 (abril 2014): 75 y ss.

(16) Giovanni Bonato, "Algunas consideraciones de cosa juzgada en el Código de Procedimiento Civil Nueva Brasil: límites objetivos y preclusiva eficacia," El Nuevo Código de Procedimiento Civil: cuestiones controversial (2015): 171-187, 186. 


\section{Perfiles generales de la cosa juzgada en el Derecho Procesal Civil brasilero Overall profiles of the res judicata in the Brazilian Civil Procedual Law}

inmutabilidad. Sin embargo, es necesario aclarar que se el motivo o la verdad de los hechos fuera una cuestión prejudicial, en el sentido técnico de la expresión, y estar sujeta a los requisitos arriba expuestos, el punto deja de ser mero motivo o verdad de los hechos y pasa a ser, obviamente, una cuestión prejudicial, y por tanto pasible de ser inmutable.

Otro de los puntos tratados también por el legislador se refieren a las relaciones jurídicas de tracto sucesivo o, como también se les llama, cosa juzgada rebus sic stantibus. Como tales relaciones poseen una condición de mutabilidad propia de la relación jurídica sometida a juzgamiento, la inmutabilidad cristalizada, para siempre, de lo establecido en la sentencia, podría resultar incoherente con la necesidad de adecuación de la inmutabilidad con justicia de la decisión. En este sentido, para las cuestiones decididas que están sujetas a cambios en el estado de hecho o de derecho, la parte podrá solicitar una revisión de lo que ha sido resuelto en la sentencia (Artículo 505)

Por último, en el campo de los límites objetivos de la cosa juzgada, en Brasil se adopta el modelo híbrido de control de constitucionalidad, en el que hay control concentrado a través de la acción directa en los tribunales, especialmente el STF, al igual que el modelo europeo; y el control difuso a través del control incidental en toda y cualquier demanda, al igual que el modelo norteamericano, en el que la inconstitucionalidad es causa petendi y no el pedido.

Respecto a esta última especie hay en el pasado reciente, cierta posición de algunos magistrados del propio STF, en defender la denominada trascendencia de los motivos determinantes en el control difuso de constitucionalidad, según la cual cuando el STF examine la constitucionalidad de un dispositivo normativo como causa petendi, por ser el Tribunal Constitucional, la decisión sobre esta cuestión vincularía los demás casos concretos, lo que de alguna manera transformaría el control difuso en un potencial control concentrado. En otras palabras, en el fondo esa teoría trasciende la decisión sobre la cuestión constitucional contenida en la cuestión prejudicial. El hecho es que tal posición ha perdido fuerza en la actual composición del STF, dado que no es asumida por la mayoría de los magistrados.

\section{Límites subjetivos}

En cuanto a los límites subjetivos, es muy tradicional la elección legislativa para restringir la autoridad de cosa juzgada a las partes entre las cuales se dictó la sentencia, quedando los terceros inmunes a cualquier inmutabilidad, ya sea para perjudicarlos, o para beneficiarlos. Ese fue siempre el sentido del artículo 472 del CPC de1973 al afirmar que "la sentencia tiene cosa juzgada entre las partes es dada, no beneficiando ni prejudicando a terceros. $\mathrm{O}$, en la máxima latina res inter alios iudicata aliis non praeiudicat. Es notoria la influencia de Liebman en la regla: la eficacia de la sentencia produce efectos erga omnes, em cuanto acto que emana de la prestación jurisdicional estatal, pero la autoridad de cosa juzgada vincula inter partes, en la medida en que el derecho en cuestión se refiere al demandante y demandado.

Más que una cuestión de tradición jurídica, por cierto, de fuerte inspiración liberal, la restricción inter partes de la cosa juzgada tiene un fundamento constitucional de no menor importancia, cual sea, la imposibilidad de la cosa juzgada afectar a terceros que no pudieran apartar la injusticia de la decisión y con eso traer violación al debido proceso legal, que en el derecho brasilero tiene expresa disposición constitucional en el artículo 5, inciso LV.

Sin embargo, como ya destacamos en sede de la doctrina (Zufelato 2011), la visión monolítica de que la cosa juzgada nunca podrá afectar a terceros es excesiva y, principalmente, no reconoce las sutilezas que la doctrina vislumbró en la interpretación de la regla derivada del derecho romano, de modo que una revisión de la tesis de que no debe haber extrapolación de la cosa juzgada pasó a ser cada vez más recurrente, ganando fuerza en importante doctrina nacional ${ }^{(17)}$. 


\section{Camilo Zufelato}

El primer paso, por tanto, fue el admitirse una cosa juzgada inter alios pero no trajese perjuicio a los terceros afectados por la autoridad de la cosa juzgada; eso significa una aceptación de la extensión de la cosa juzgada para beneficiar y no para perjudicar a los terceros. Esse es el sentido del artículo 274 del Código Civil Brasilero de $2002^{(18)}$, sobre el tema de la solidaridad activa de acreedores, que fija como presupuesto una extensión de la cosa juzgada para beneficiar a terceros acreedores solidarios en el proceso, pero nunca hacerles daño. Otro ejemplo, no legislado, sería el tema clásico de la reunión de resolución de recurso de anulación interpuesto por una de las partes interesadas.

Con la llegada del CPC de 2015, el código da un paso importante hacia una nueva imposición de la regla de los límites subjetivos de la cosa juzgada, en los términos del Art. 506: la sentencia tiene calidad de cosa juzgada entre las partes entre las que se da, no perjudicando a terceros. Aunque no ha dicho expresamente la regla en su integridad, la mayor parte de la doctrina ha interpretado el dispositivo con el fin de complementar los términos legales para añadir él, y no hacer daño a otros, en beneficio de ellos. En otras palabras, sería una especie de cosa juzgada secundum eventum litis, tal como se extendería a terceros sólo para su beneficio, no para hacerles daño.

Sin duda hay un reconocimiento de que el CPC 2015 se habría afiliado a la doctrina reciente, en vigencia del CPC de 1973, que apoyó la extensión del juicio en favor de terceros ${ }^{(19)}$, pero el hecho es que no es todavía bajo los auspicios del nuevo código, buena doctrina que efectivamente se ha ocupado de una manera detallada y consolidada sobre las posibilidades de derecho sustantivo que se relacionan con situaciones jurídicas de terceros.

Baste mencionar, a título de ejemplo, que en el propio CPC de 2015 hay reglamentación, original hasta entonces, de la figura denominada de incidente de resolución de demandas repetitivas ${ }^{(20)}$, con el objetivo de proponer una solución a las situaciones jurídicas de masa, de naturaleza individual, pero con gran expresión numérica, a partir del juzgamiento por muestra de conflictos repetitivos, por medio de la instauración de un incidente procesal junto a los tribunales de segundo grado, con la concomitante suspensión de las demandas individuales, esperando el juzgamiento de los incidentes para que, de inmediato, el resultado pase a vincular a los titulares de estos derechos individuales sin cualquier temperamento, vale decir, sea para beneficiarlos, sea para perjudicarlos(21). Esto demuestra cómo una norma específica aplicable a un tipo de conflicto que son las demandas repetitivas,

(17) Egas Moniz Aragão, "Comentarios sobre los límites subjetivos da juzgados cosa," Revista de los Tribunales Año 67, 625 (noviembre 1987): 7-26; William Estellita, La cosa juzgada: legal y Fundación Tercera prórroga (Río de Janeiro, 1936); José Carlos Barbosa Moreira, "Cosa juzgada: subjetivos Me extensión. litispendencia. acción de nulidad de la patente," Procedimiento Civil, Derecho (1971): 273-294; José Carlos Barbosa Moreira, "Activar la solidaridad: oración y efectos de cosa juzgada en la propuesta de la acción de cobro solamente Prestamista zumbidos," Lawyer Magazine AASP, año XXV, 84: 67-72, deteriorarla. 2005; Willis Santiago Guerra Filho, "Ultrassubjetiva eficacia de la sentencia, se requiere acumulación y el principio contradictorio hacen," Revista Proceso, año 21, 84 (1996): 264-267; Eduardo Talamini, "Partes, los terceros y cosa juzgada (los límites subjetivos de la cosa juzgada)," En: Fredie Didier Junior; Teresa Arruda Alvim Wambien, Aspectos controvertidos y actuales en los terceros en los procedimientos civiles y asuntos relacionados (Sao Paulo: Revista de los Tribunales, 2004).

(18) Artículo 274. El juicio en contra de uno de los acreedores solidarios no afecta a la otra, pero el juicio ventaja favorable para ellos, sin perjuicio de las excepciones personales que el deudor tiene derecho a confiar en relación con cualquiera de ellos.

(19) José Rogério Cruz e Tucci, Limites subjetivos da eficácia da sentença e da coisa julgada (São Paulo: Revista dos Tribunais, 2006); TUCCI, José Rogério Cruz e Tucci, "Limites subjetivos da eficácia da sentença e da coisa julgada nas ações coletivas," Revista de Processo, ano 32, vol. 143 (2007): 42-64.

(20) Véanse los artículos 976 y siguientes CPC 2015.

(21) Véanse específicamente el artículo 985 del CPC de 2015. 


\section{Perfiles generales de la cosa juzgada en el Derecho Procesal Civil brasilero Overall profiles of the res judicata in the Brazilian Civil Procedual Law}

difiere y contraria a la regla general en cuanto a la extensión de la cosa juzgada a terceros.

Por último, el cambio de paradigma con respecto a un régimen processos inter partes para um inter alios sin perjudicar a los terceros todavía no tiene ninguna señal de amplio construcción sistemática que permita afirmar con seguridad, para donde está apuntando la nueva regla.

\section{Cosa juzgada en el proceso colectivo}

La tutela jurisdicional colectiva brasileña es reconocidamente compuesta por um un sistema próprio y bastante peculiar, marcado por diversas questiones originales sin precedentes, al menos idénticas, en otros sistemas de derecho comparado. Es claro que recibió una fuerte influencia de la doctrina italiana de finales de los años setenta, y de la necesidad de establecer ondas renovadoras de acceso a la justicia, en este caso concreto em lo referido a los derechos transindividuales, pero la doctrina brasileña construyó un sistema sui generis en diversos aspectos.

Desde los primeros pasos hacia la construcción del sistema brasileño de procesos colectivos en los inicios de los años ochenta (Grinover 1984), siempre se tuvo en cuenta en la medida de lo posible, y en primer lugar, la cultura y la capital jurídico nacional antes de cualquier importación extranjera.

Sobre la cuestión de cosa juzgada esta dimensión de fuerte atractivo nacional es ejemplar. Consciente de la necesidad de extrapolar los límites subjetivos de la cosa juzgada para alcanzar a todos aquellos que se sometían a la situación jurídica de naturaleza transindividuales llevado a los tribunales por un colectivo legitimado con clara actuación por fuerza de susbtitucón procesal, era necesario romper con el esquema de la cosa juzgada inter partes, mencionada en el punto anterior por ser peculiar del sistema individual del CPC de 1973, para una cosa juzgada que afecte terceros, pero ahora con la preocupación de no traeles perjuicios, ya que ello podría entrar en conflicto con las garantías constitucionales del debido proceso $^{(22)}$.

En el proceso colectivo, en función a la indivisibilidad de los derechos difusos y colectivos, o la misma necesidad de un tratamiento uniforme de los derechos divisibles, como son los individuales homogéneos, la regla es una proceso erga omnes, expresión que designa, en el caso de las acciones colectivas una extensión subjetiva que abarca la situación jurídica tutelada, sean cuantos fueran los sujetos que en ella se encontraren. Es cierto que debido a esta amplia extensión de la autoridad de una decisión (en algunos casos inclusive a nivel nacional) provocó una reacción nefasta y violadora de derechos, claramente inconstitucional, del Poder Público, que intentó imponer limitaciones territoriales a los límites erga omnes de la cosa juzgada colectiva ${ }^{(23)}$, pero afortunadamente, a pesar de que nunca había sido declarada inconstitucional por el STF, la disposición legal artículo 16 de la ley de acción civil pública, ha tomado distancia para su aplicación por el STJ.

(22) Antonio Gidi, Cosa juzgada y la litispendencia en la acción colectiva (Sao Paulo: Saraiva, 1995); Ada Pellegrini Grinover, "Las acciones colectivas de América Latina: nuevas preguntas sobre la legitimidad y la autoridad de cosa juzgada," Revista Forense, vol. 361, no. 98 (2002): 03-12; Ada Pellegrini Grinover, "De cosa juzgada en el Código de Protección al Consumidor," Revista Abogado 33 (1990): 5-15; Ada Pellegrini Grinover, Código de protección del consumidor brasileño comentado por los autores del anteproyecto $10^{a}$ ed. (Río de Janeiro: Forense, 2011); Ada Pellegrini Grinover, "Cosa juzgada erga omnes, litis secundum y secundum probationem eventum," Revista Forense, año 101, 380 (2005): 3-19; Rodolfo de Camargo Mansuco, Colectivos de jurisdicción y cosa juzgada: teoría general de la acción colectiva, $2^{a}$ ed. (Sao Paulo: Revista de los Tribunales, 2007); Rodolfo de Camargo Mansuco, "Cosa juzgada, stoppel garantía y eficacia preclusiva secundum eventum litis," Revista de los Tribunales, v. 75, 608 (1986): 23-33; Ronaldo dos Santos Lima Santos, "Magnitud de cosa juzgada en las acciones de classe," Revista Proceso, año 31, 142 (2006): 42-58.

(23) José Marcelo Menezes Vigliar, "Ley 9494 de 10 de septiembre de 1997, y la nueva disciplina de la cosa juzgada en las acciones de clase: inconstitucionalidad," Revista de los Tribunales, v. 86, 745 (1997): 67-72. 
Camilo Zufelato

En este sentido, la Ley 7.347 / 85, al instituir la denominada acción civil pública, siguió el camino de la Ley 4.717 / 65 y se mantuvo fiel a la formación de cosa juzgada sólo en los casos de procedencia o improcedencia con suficiencia probatoria, quedando inmune la decisión que declara la demanda improcedente con insuficiencia probatoria, hipótesis en la cual podría ser propuesta otra demanda teniendo en consideración nuevas pruebas, ya que hay la formación de cosa juzgada materail sino sólo formal. Esta solución tiene la clara intención de luchar contra una decisión de carácter fraudulento, que podría haber sido realizada sin el rigor que se espera del autor de una demanda colectiva, riesgo que es potencialmente mayor en esquemas de legitimación activa concurrente y disyuntiva sin un rigurososo sistema de control judicialsobre la representación adecuada del ente autor de la demanda.

Esta solución legislativa creativa fue denominada de cosa juzgada secundum eventum litis, dando nueva vida a un principio procesal que siempre ha sido muy combatido por los procesalistas en función de una posible desigualdad que le sería inherente, ya que concede una clara ventaja a la colectividad en la medida en que la improcedencia conbinada por la insuficiencia de pruebas no blinda el resultado del proceso, permitiéndose nueva discusión. El hecho es que es necesario tener en consideración la magnitud de los derechos en juego, y especialmente la elección político-jurídica a la que miraba el legislador brasilero, cual sea, para escapar de un régimen procesal como el norteamericano, en el cual existe el presupuesto de un control estricto sobre la representación adecuada del legitimado, así como establecer mecanismos de opt in o opt out que siempre parecerán, a los ojos de muchos especialistas, incompatibles con el perfil jurisdiccional brasilero.

El hecho es que con la entrada en vigor del código de defensa del consumidor en 1990, el microsistema procesal colectivo brasilero se perfecciona todavía más al contemplar la tutela colectiva de los derechos individuales homogéneos, oportunidad en la que se mantuvieron las líneas generales de la cosa juzgada establecida por la ley de la acción civil pública, pero innovando con respecto al aprovechamiento, en la esfera individual del titular de un derecho con expresión colectiva, de la cosa juzgada formada en una acción colectiva, permitiéndole la liquidación y ejecución del título ejecutivo constituido en la fase colectiva, una verdadera utilización in utilibus de la cosa juzgada colectiva, al mismo tiempo en que prohíbe que el juzgado perjudique la esfera individualde los individuos, en los términos del artículo 103 del código de defensa del consumidor.

Esos tratamientos que la cosa juzgada recibe en el ámbito de la tutela colectiva brasilera denominada de formación de cosa juzgada erga omnes secundum eventum probationis Litis vel probationis resultado del proceso combinado con la suficiencia o no de pruebas (y la extensión de la cosa juzgada secundum eventum litis in utilibus) se extiende a la esfera individual de los miembros del grupo o colectividades solamente para beneficiar, nunca para perjudicar (Zufelato 2011).

Sin embargo, un tema ha llamado la atención recientemente en Brasil sobre los conflictos de naturaleza colectiva: la posibilidad de que la presentación de la demanda no a favor de una colectividad, pero sí contra de lo que se ha denominado la acción colectiva pasiva. Este fenómeno, que en países como los Estados Unidos se conoce como defendant class action, en Brasil no tiene autorización legal expresa, una vez que el legislador, en principio, al instituir la tutela colectiva en el país, ciertamente tenía la intención de promover la defensa del grupo, y no su control. Sin embargo, hay un creciente ingreso, desde un punto de vista jurisprudencial, de prácticas procesales que en realidad son verdaderas acciones contra grupos, colectividades que al ejercer derechos colectivos se exceden y violan los derechos de otros grupos, en la dinámica social(24).

(24) Camilo Zufelato, "Acción de clase demandada en la legislación brasileña: la necesidad de una regulación legal," En: María Clara Gozzolini; Mirna Cianci; Petronio Calmon; Rita Quartieri (Org.) En defensa de un nuevo sistema de procesos colectivos: Estudios en honor de Ada Pellegrini Grinover (Sao Paulo: Saraiva, 2010): 89-142. 


\section{Perfiles generales de la cosa juzgada en el Derecho Procesal Civil brasilero Overall profiles of the res judicata in the Brazilian Civil Procedual Law}

A pesar de que este tipo de acciones sean una modalidad de acción colectiva, poseen muchas peculiaridades que las distinguen de las demandas propuestas por colectivos legitimados, por lo que el régimen jurídico de la cosa juzgada se opone frontalmente a la regla general del secundum eventum litis mencionado líneas arriba. En la acción colectiva pasiva, es necesario que la orden judicial vincule obligatoriamente a todos los miembros del grupo, bajo pena de tornarse absolutamente inofensivo; en otras palabras, la cosa juzgada alcanza a los terceros independientemente del resultado, pro et contra.

Sin embargo, esta solución debe ser equilibrada con el respeto a los intereses de los miembros de la colectividad, que son terceros a ser afectados por una decisión les es desfavorable. En este sentido, la condición sine qua non para la cabida y la admisión de la acción colectiva pasiva que sea propuesta em face de un representante adecuado de toda la colectividad, la cual desempeña una defensa en el proceso en términos del debido proceso legal sustancial, con el fin de autorizar que el mandato judicial vincule, inclusive para perjudicar, a los miembro de la colectividad a la cual representan.

\section{Referencias Bibliográficas}

Barbosa Moreira, José Carlos. 1971. Aún así y siempre la cosa. Derecho Procesal Civil. Ensayos y Opiniones: 133-146.

Camilo Zufelato. 2011. Cosa juzgada colectiva. Sao Paulo: Saraiva.

Grinover, Ada Pellegrini (Coord.) 1984. La protección de los intereses difusos. Sao Paulo: Max Limonad. 